\title{
1978 Presidential Address of the Society for Pediatric Research
}

\author{
April 27, 1978 \\ FRANK A. OSKI \\ Department of Pediatrics, Upstate Medical Center, State University of New York, Syracuse, New York, USA
}

I have chosen for my presidential address the topic "Metal and Mentors." Although this appears to be an improbable combination I believe that several analogies exist between the two and both have deep personal meaning for me.

The metal I refer to is iron. Among metals it is second only to aluminum in its abundance in the earth's crust. Despite its abundance it is the leading nutritional deficiency among infants here in the United States.

The mentors I refer to are all of us-members of medical school faculty. Among pediatricians we are second only in numbers to the practicing physicians. Despite our abundance we continuously hear that insufficient research is being conducted within our departments, and, even more troubling, that careers in what we term "academic medicine" no longer attract many of our brightest and most enthusiastic students and house officers.

Iron deficiency remains a problem because for too long we failed to appreciate the importance of the bioavailability of the iron in the nutrients we allowed infants to eat. We forgot many of the important lessons of the past. Even today we fail to appreciate that iron deficiency produces more than anemia and is, in fact, responsible for a variety of systemic dysfunctions.

Similarly, I believe that the decline in research activities among faculty and our failure to attract our best students into careers in academic medicine also stems in part from a lack of bioavailability. In this instance I refer to the lack of visible and available mentors. Here too we have forgotten many of the important lessons from our past. Research deficiency also produces a variety of systematic dysfunctions.

Let me attempt to develop both these themes recognizing the inherent dangers in exploiting analogies and trying to combine philosophy with science.

My two mentors-Dr. Lewis Barness and Dr. Louis Diamond-were both interested in iron. They asked many of the questions I am still trying to answer today. They both showed, in different ways, the joys of inquiry. Both possessed the ability to distinguish between ideas and good ideas. Both emphasized that either a negative or a positive result was valuable if the question that was asked was properly framed and of sufficient importance. Both could criticize in a way that encouraged renewed efforts rather than retreat. Most importantly, both were visible, available, and taught by example.

How many mentors are visible or available to our students and house officers today? Do students and house officers witness clinical research in progress? The development of Clinical Research Centers has been a force to sequester patient-focused research activities in many institutions. The availability of sophisticated equipment has driven many of us to the laboratory where we remain unseen by the young potential investigator. The availability of adequate, if not generous, federal research support has made many potential investigators equate the academic life with the writing of grants. After all, this may be all they see their potential models doing or hear them talking about. Some young faculty even conclude that they cannot conduct research because they don't have a grant. Are there enough mentors that demonstrate otherwise?

The critical role of a mentor in the moulding of a young person's life has been admirably documented in a recently published book by Daniel Levinson entitled The Seasons of a Man's Life (1). Levinson and his associates reconstructed the lives of 40 men between the ages of 35 and 45 largely through intensive interviews. The researchers also studied the biographies of great men such as Ghandi and Luther as well as memorable characters from novels and plays, comparing their development with that of their study subjects. Levinson and his colleagues were able to identify a number of eras in the male life cycle. These would presumably apply to females as well, although they were not studied (Fig. 1). Each era, lasting about $2 \vec{j}$ years, contains a series of growth periods defined by the developmental tasks an individual must perform at this time in the life cycle. The novice phase is a crucial period that lasts some 15 years, beginning at about age 17. The developmental tasks of this period include: forming the dream, forming a mentor relationship, forming an occupation, forming a marriage and family.

I would like to enlarge on this second and perhaps most important of all tasks in the context of the young investigator. Levinson states, "The most crucial developmental function of a mentor is to support and facilitate the realization of the dream. The 'true mentor' fosters the young adult's development by believing in him, sharing the youthful dream and giving it his blessing, helping to define the newly emerging self in its newly discovered world, and also creating a space in which the young man is able to form a reasonably satisfactory life structure that contains the Dream."

The mentor's primary function is to be a transitional figure, one who fosters the young person's development. The mentor is a mixture of parent and peer. If he is too much a peer, he cannot represent the advanced level toward which the younger person is striving. If he is too parental, it is difficult for both of them to overcome the generational difference and move toward the peer relationship that is the ultimate, though never realized, goal. The mentoring relationship lasts perhaps 2 or 3 years on the average, 8-10 years at most. Sometimes it comes to a natural end or it may end with strong conflict and bad feeling. After the separation the younger person may adopt many of the qualities of the mentor. His personality is enriched as he makes the mentor a more intrinsic part of himself. The internalization of models is a major source of development in adulthood.

Are we who have chosen careers in academic pediatrics with a commitment to inquiry adequately assuming our responsibility as mentors? Is our failure the reason we see fewer of our young people infused with a spirit of inquiry? I believe it is partially responsible for the problem. Many have blamed the problem of failure to recruit good people to biomedical research and academic medicine to changes in federal funding policies and changes in public attitudes. Bogdonoff has demonstrated that this problem antedated the changes in federal funding and public attitudes. To 


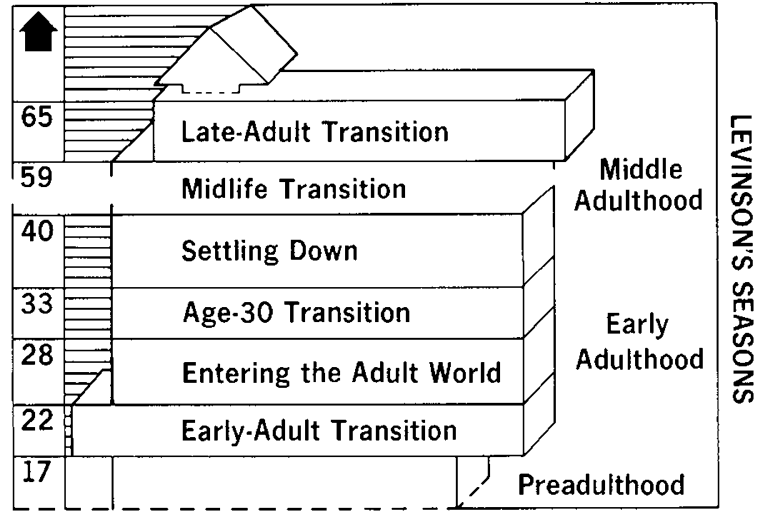
(1).

Fig. 1. From The Seasons of a Man's Life. Redrawn from Levinson

continue to use funding policies as scapegoats allows us to ignore the problem. One component of the problem may be ourselves: our lack of availability, our failure to bring the research to the patient in full view of students and house officers.

Another source of the problem is the airplane. The ease of travel has resulted in a proliferation of scientific conferences, visiting professorships, and other reasons for spending more and more time away from the institution, thus contributing to a lack of availability and visibility. It has been claimed that if an individual spent a week in Chicago's O'Hare Airport one could expect to see at least $50 \%$ of all the investigators who made an important scientific contribution in the previous year. If this is the case, then the investigator would get to know the young Hara Krishna better than his own students, house officers, and fellows.

The importance of the mentor has been recognized since antiquity, documented in Greek and Roman writings, acknowledged by most of us, but practiced by few of us. Henry Adams wrote, "A teacher affects eternity; no one can tell where his influence stops." Jacques Barzun most clearly described our present situation when he wrote, "Teaching is not a lost art, but the regard for it is a lost tradition."

From the mentor to the metal. Both my mentors, Drs. Barness and Diamond, were interested in iron but for different reasons. Dr. Barness had convinced me, through his own work and by introducing me to the literature, that breast milk was the perfect food for infants and their only required nutrient for the first 8 to 12 months of life. Parenthetically I might add that I am certain that Dr. Barness developed this view as a result of his contacts with one of his own mentors, the late Paul Gyorgy. If Gyorgy were alive today I think he would be willing to accept the fact that his source for this nutritional concept came directly from God.

The problem was thus formed. How could breast milk, with an iron content of $0.6-1.0 \mathrm{mg} /$ liter provide for the iron needs of infants during the first year of life when the feeding of cow milk with an almost identical iron content routinely resulted in the infant developing iron deficiency anemia? The fact that exclusively breast-fed infants did not develop pallor or anemia had been generally accepted as evidenced by the statements that appeared in the testbooks of pediatrics that were published at the turn of the present century. The following statement appears in Pfaundler and Schlossmann's textbook The Diseases of Children (2) published in 1908. In the chapter on Diseases of the Blood and of the Blood-Forming Organs, Dr. Japha of Berlin wrote, "There are always a number who, after the period of nursing has come to an end, are conspicuous because of their pale complexion.... In breast-fed children serious cases hardly ever occur." Statements of a similar nature appear in virtually all of the textbooks of the time. In 1928 Mackay (3) tested this hypothesis when she investigated the hemoglobin status of a group of infants who were exclusively breast-fed for the first 7 months of life. The breast-fed infants had persistently higher hemoglobins than the artificially fed group; the difference between the two groups declined after supplementation with other foods was begun. In work that was largely ignored, Fueillen (4) in 1954, employing a balance technique, measured iron absorptions of 45 and $75 \%$ in two breast-fed infants studied. It wasn't until 1976 that studies employing radioiron clearly demonstrated the superior bioavailability of the iron from human milk. Saarinen and coworkers (5) have now demonstrated that iron absorption from human milk averages $50 \%$ in contrast to an average absorption of only $5-10 \%$ from whole cow milk. Figure 2 depicts the percent iron absorption and the amount of iron absorbed from various forms of milk. The data is a composite of studies performed by Saarinen and coworkers (5), Nathan Smith and colleagues (6), and work done in our own laboratory $(7,8)$.

The reason that the iron in human milk has such an enhanced bioavailability is still unknown. It does not appear to be simply the result of its calcium and phosphorus content, its low protein concentration or the presence of lactoferrin (8), taurine (9), reduced glutathione (9), or inosine (9) in the human milk.

It has taken us almost three-quarters of a century to rediscover what had already been known. Breast milk, and breast milk alone, can adequately nourish infants throughout most of the first year of life. If we looked at the infants and kept asking the questions the truth would not have eluded us so long. Dr. Barness was right, Dr. Gyorgy was right, and, again, parenthetically, God was right.

Dr. Diamond was also interested in iron. Having seen literally thousands of infants with iron deficiency anemia he was more impressed by the nonhematologic manifestations of the disease. As each iron-deficient infant was presented to him he took particular delight in pointing out to us the other features so characteristic of these infants-their irritability, apathy, anorexia, growth failure, cheilosis, and spoonnails. These findings had been appreciated by clinicians at the turn of the century. Again quoting from the textbook by Pflaunder and Schlossman the infants were described as "peevish, ill at ease, and listless". Dr. Diamond was also quick to point out how rapidly these symptoms disappeared once iron therapy was instituted-often in a matter of 2-3 days. This improvement always preceded any significant change in the patient's hemoglobin level. Dr. Diamond recalled that when he was a house officer many of these infants were mistakenly believed to be suffering from disorders of thyroid function. Why? he would ask.

Clement Finch and his associates (10) have made an important contribution to our understanding of the effects of iron deficiency that are independent of the anemia it produces. It is known that iron deficiency anemia limits the work capacity of the experimental animal and of man. It has been generally assumed that the decreased work performance was due to the limiting effect of anemia on oxygen delivery to the musculature. Fatigue and weakness have been attributed to iron deficiency alone by some but a causal relationship has been difficult to establish. To Finch it seemed possible that a lesion in the muscle might exist but be

\section{IRON ABSORBED}

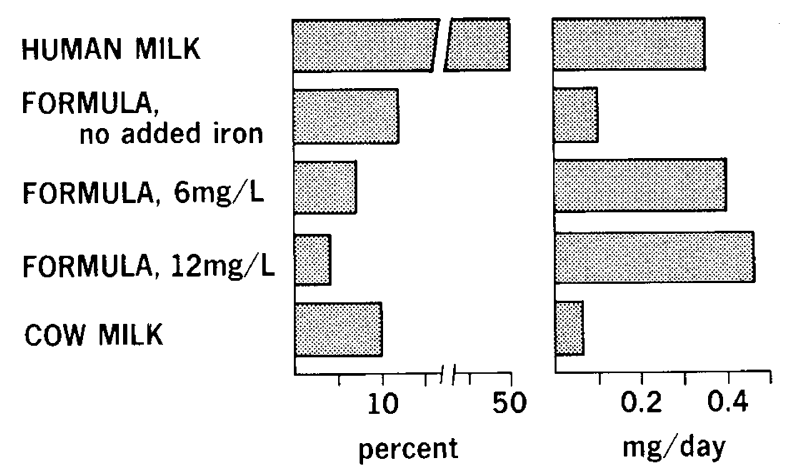

Fig. 2. Percentage of iron absorption and absolute quantities of iron retained from human milk, a variety of proprietary infant formulas, and cow milk. Data derived from numerous investigators (5-8). 
obscured by the presence of anemia.

Rats were selected for study. In preparation for measurements of running ability, rats were trained on a small animal treadmill. After training, a polyethylene catheter was placed into the superior vena cava via the jugular vein. The catheter was used to remove or add blood to these animals so that all groups had similar hemoglobin values independent of their diets. In the first study four groups of rats were tested. Rats in group A were maintained on an iron-deficient diet for 4 weeks prior to the testing period. Rats in group $B$ received a normal diet. Rats in a third group were fed the iron-deficient diet and received supplemental iron during the 4-week period. A fourth group of rats was fed the same iron-deficient diet for 4 weeks and then started on iron therapy after the initial exercise testing was completed on the first day of the study. All groups were maintained at a hemoglobin level of approximately $10 \mathrm{~g} / 100 \mathrm{ml}$. In Figure 3 it can be noted that the rats fed the iron deficient diet were only able to run for $4 \mathrm{~min}$ in contrast to rats who received a normal diet or an iron-deficient diet supplemented with iron who had mean running times of 16-20 min. Most striking, however, were the results observed in the rats fed the iron-deficient diet and then placed on iron on day 0 . The running time, initially $4 \mathrm{~min}$, increased to $10 \mathrm{~min}$ after 1 day of iron, was $15 \mathrm{~min}$ after 2 days, and was indistinguishable from the normal animals after 3 days. This was the effect of iron and not of correction of anemia, all groups having a similar hemoglobin concentration.

In a second set of experiments (Fig. 4) employing the same diets, all animals were made initially anemic and then transfused on days 2, 4, and 7. The hemoglobin of all groups increased simultaneously from $6 \mathrm{~g}$ on day 0 , to $8 \mathrm{~g}$ on day 2 , to $10 \mathrm{~g}$ on day 4 , and to $12 \mathrm{~g}$ on day 7 . Running time was markedly reduced in all groups at the beginning of the study. The two groups with adequate iron increased their work performance to near maximum

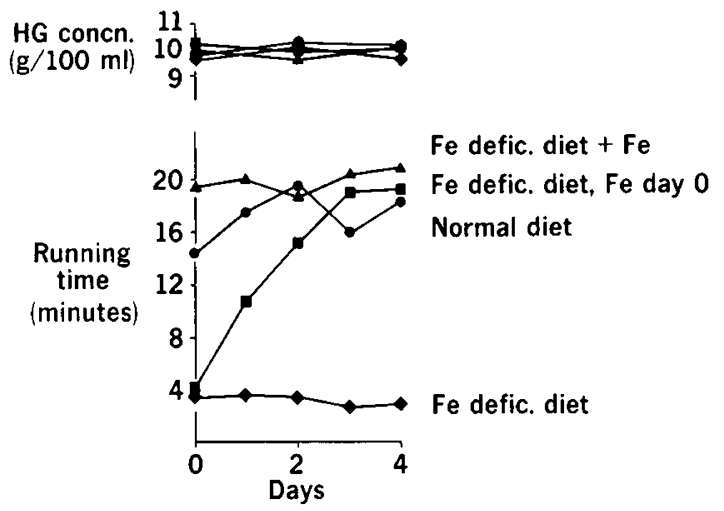

Fig. 3. Effect of iron therapy on running time on treadmill in four groups of rats. Hemoglobin maintained constant. See text for details. Data redrawn from Finch et al. (10).

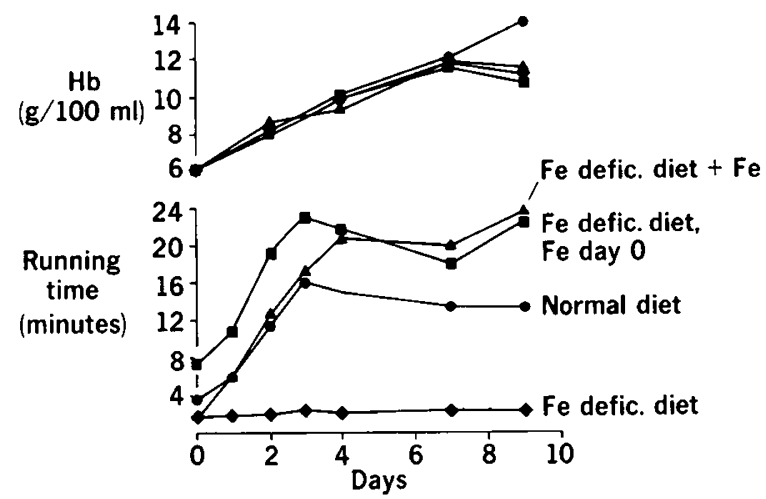

Fig. 4. Effect of iron therapy on running time on treadmill in four groups of rats. Hemoglobin increased by transfusion during course of study. See text for details. Data redrawn from Finch et al. (10). values by the third day despite the fact that the hemoglobin was only $9 \mathrm{~g} / \mathrm{dl}$ at that time. The iron deficient animals treated with iron on day 0 showed a maximal running time, with a mean of greater than $20 \mathrm{~min}$ by day 4 . The animals with iron deficiency whose hemoglobin had been raised by transfusion showed no significant change in their running time over a period of 9 days from the original mean value of $2 \mathrm{~min}$. Again it was clear that iron deficiency, independent of anemia, limited exercise function.

When muscle metabolism was studied in these iron-deficient animals further insight into the problem was obtained. Concentrations of the cytochrome pigments, and myoglobin, and rates of oxidative phosphorylation with pyruvate-malate, succinate, and $\alpha$-glycerophosphate as substrates were all reduced in mitochondrial preparations from skeletal muscle of iron-deficient rats, but only the rate of phosphorylation with $\alpha$-glycerophosphate as substrate increased significantly and in parallel with the recovery of work performance of the iron-deficient rats treated with iron. Mitochondrial $\alpha$-glycerophosphate oxidase isolated from skeletal muscle is a non-heme iron containing enzyme, and it would appear that this is the site of the biochemical abnormality of muscle that accompanies iron deficiency and limits muscular performance.

Clues to a biochemical basis for the behavioral alterations that accompany iron deficiency are also beginning to emerge. As previously stated, clinicians for many years suspected that the iron deficient infant or child behaved in an altered fashion. Despite this the reports of Howell and Beller (11) and of Sulzer and associates (12) that children with iron deficiency had lower IQ scores, decreased attentiveness, restricted perception, and impaired performance on measures of latency and associative reactions were greeted with great interest. Interest that was surpassed by skepticism.

The hypothesis that iron deficiency may alter behavior has taken on some measure of credibility by virtue of the observations that monamine oxidase-like activity is decreased in the livers and brains of iron-deficient rats (13) and in the platelets of humans (14). This decrease in monamine oxidase activity is associated with alterations in catecholamine metabolism in the rat. In a similar fashion iron deficiency produces an increased urinary excretion of norepinephrine in infants and children that promptly returns to normal when iron therapy is instituted (15) (Fig. 5).

We recently reported a study (16) that suggests that behavioral alterations can be documented to be present in iron-deficient

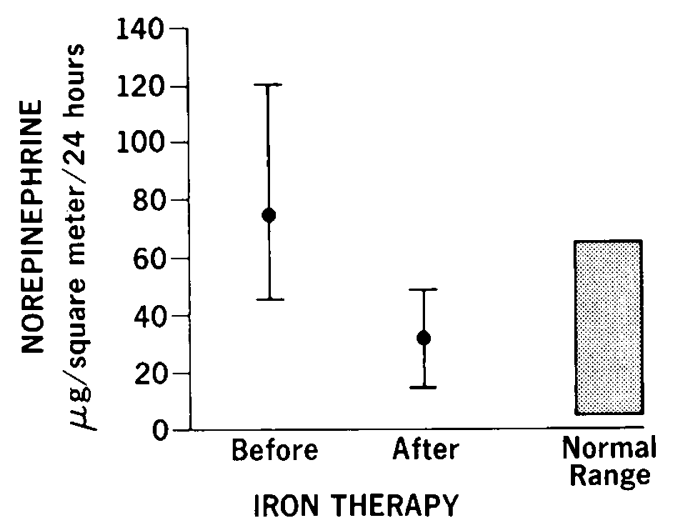

Fig. 5. Effect of intramuscular iron therapy on 24-hr urine norepinephrine excretion in patients with iron deficiency anemia. Data redrawn from Voorhess et al. (15).

Table 1. Bayley test scores of Mental Development Index

\begin{tabular}{crcc}
\hline Group & Pretest & Post-test & $P$ \\
\hline Control & 90.6 & 96.6 & NS \\
(12) & \pm 15.0 & \pm 17.4 & \\
Iron treated & 96.3 & 109.8 & 0.01 \\
(12) & \pm 9.8 & \pm 9.2 & \\
\hline
\end{tabular}


infants. Twenty-four infants with iron deficiency anemia, ages 9-26 months, were randomly assigned to a treatment group and control group. Bayley Scales of Infant Development were administered before treatment with intramuscular iron or placebo; the test was readministered in 5-8 days (Table 1). Children treated with iron showed a significant increase in their scores on the Mental Development Index averaging a mean gain of 13.6 points in a mean time of 6.8 days. When subsets of the test were examined, it was found that the treated group was judged to have become more alert and attentive. Obviously a finding of this type, with its broad social implications, needs to be confirmed by other investigators using larger numbers of subjects and other testing techniques. I suspect that the results will be confirmed. My belief is not based on our preliminary findings but the long standing clinical observations of others and the insight of my mentor.

In closing I would like to thank the Society for the honor they have bestowed upon me and for the privilege of talking to a large captive audience. More importantly, I would like to urge all of you to remember that the presence of research, like the presence of iron, does not insure its availability to others. Nature has proven that the manner in which it is presented determines its effect. Test your mettle-be a mentor.

\section{REFERENCES}

1. Levinson, D. J.: In: The Seasons of a Man's Life (Alfred A. Knopf, Inc., New York, 1978).

Copyright (C) 1978 International Pediatric Research Foundation, Inc $0031-3998 / 78 / 1212-1145 \$ 02.00 / 0$
2. Pfaundler, M., and Schlossmann, A.: In: The Diseases of Children (Lippincott, Philadelphia, 1908).

3. Mackay, H. M. M.: Arch. Dis. Child., 3: 1175 (1928).

4. Feuillen, Y. M.: Acta Paediat., 43: 181 (1954).

5. Saarinen, V. M., Siimes, M. A., and Dallman, P. R.: J. Pediat., 91: 36 (1977).

6. Smith, N. J., Rosello, S., Say, M. B., and Yeya, K.: Pediatrics, 16: 166 (1955).

7. McMillan, J. A., Landaw, S. A., and Oski, F. A.: Pediatrics, 58: 686 (1976).

8. McMillan, J. A., Oski, F. A., Lourie, G., Tomarelli, R. M., and Landaw, S. A.: Pediatrics, 60: 896 (1977).

9. Oski, F. A.: Unpublished observations.

10. Finch, C. A., Miller, L. R., Inamder, A. R., Person, R., Seiler, K., and Mackler, B.: J. Clin. Invest., 58: 447 (1976).

11. Howell, D., and Beller, K.: Summary, Proceedings of Workshop of the Food and Nutrition Board, National Academy of Sciences, Washington, DC, 1971.

12. Sulzer, J. L., Wesley, H. H., and Leonig, F.: Nutrition, Development and Social Behavior, DHEW Publication No. 73-242, 1973.

13. Symes, A. L., Missala, K., and Sourkes, T. L.: Science, 174: 153 (1971).

14. Youdim, M. B. H., Woods, H. F., Mitchell, B., and Callendar, S.: Clin. Sci. Mol. Med., 48: 289 (1975).

15. Voorhess, M. L., Stuart, M. J., Stockman, J. A., and Oski, F. A.: J. Pediat., 86: 542 (1975).

16. Oski, F. A., and Honig, A. S.: J. Pediat., 92: 21 (1978).

Printed in U.S. A. 